\title{
Effects of Notchplasty on Anterior Cruciate Ligament Reconstruction: A Systematic Review
}

\author{
Francesco Ranuccio $^{1}$ Filippo Familiari ${ }^{1}$ Giuseppe Tedesco ${ }^{1}$ Francesco La Camera ${ }^{1}$ Giorgio Gasparini ${ }^{1}$ \\ ${ }^{1}$ Department of Orthopaedic and Trauma Surgery, Magna Graecia \\ University of Catanzaro, Catanzaro, Italy \\ Joints 2017;5:173-179.

\begin{abstract}
Address for correspondence Filippo Familiari, MD, Department of Orthopaedic and Trauma Surgery, Magna Graecia University of Catanzaro, Campus "S. Venuta," V.le Europa (Loc. Germaneto), 88100 Catanzaro, Italy (e-mail: filippofamiliari@gmail.com).
\end{abstract}

\begin{abstract}
Keywords

- knee

- notchplasty

- anterior cruciate ligament

- reconstruction

- review
\end{abstract}

Purpose Notchplasty is a complementary surgical procedure often performed during anterior cruciate ligament reconstruction (ACLR) with the aim to widen the intercondylar notch and to avoid graft impingement. The aim of this review was to analyze the current literature evidence concerning the effects of notchplasty on clinical outcome after primary ACLR.

Methods Cochrane Database of Systematic Reviews, the Cochrane Central Register of Controlled Trials, PubMed, and MEDLINE were used to search English language studies, from January 1990 to July 2015, concerning the effects of the notchplasty on ACLR, using the following keywords: "ACL" OR "anterior cruciate ligament" OR " $A C L$ reconstruction" OR "anterior cruciate ligament reconstruction" AND "notch" OR "notchplasty" OR "intercondylar notch". Randomized and nonrandomized trials, case series, technical notes, biomechanical studies and radiological study were included.

Results At the final screening 16 studies were included. Despite widely used, the usefulness of notchplasty during ACLR remains unclear. Some concerns emerged regarding potential harmful effects of notchplasty, mostly related to the knee biomechanics and postoperative blood loss. Notchplasty can be useful in the treatment of arthrofibrosis and in presence of bony spurs of the notch both in primary and revision surgery. However, the level of evidence of available literature is poor and there is a strong need for randomized controlled trials investigating the role of notchplasty on ACLR.

Conclusion We suggest being aware of potential complications following notchplasty during ACLR before deciding to perform notchplasty in primary ACLR, reserving it for the surgical management of arthrofibrosis, treatment of notch osteophytosis and revision ACLR. Level of Evidence Level IV, systematic review of level II-IV studies.

\section{Introduction}

The anterior cruciate ligament (ACL) is among the most commonly ruptured ligaments with 100,000 to 200,000 injuries, ${ }^{1}$ and more than 100,000 estimated primary anterior cruciate ligament reconstructions (ACLR) performed yearly only in the United States. ${ }^{2}$

Notchplasty is an ancillary surgical procedure, historically conceived and developed with the aim to widen the intercondylar space and avoid the graft/notch impingement. Notchplasty is considered a useful step especially in the traditional transtibial single-bundle ACLR technique, whereas the femoral tunnel is made at the isometric point on the lateral wall of the femoral notch. ${ }^{3,4}$ With the advent of transportal techniques, the need for notchplasty has been decreasing, even if it is still mostly performed. ${ }^{5}$ Although notchplasty is easily and quickly feasible, there is still a lack of evidence related to volume and location of an eventually required notchplasty, 2,6 as well as its effect on the outcome of ACLR. ${ }^{4}$ Little is known about long-term consequences of this procedure, leaving surgeons mostly free to choose following their background. Moreover, a growing body of laboratorybased research instilled the suspicion that notchplasty could adversely affect graft integration, knee biomechanics as well as the surrounding cartilage, ${ }^{7-9}$ but these aspects are still debated, and not yet fully understood. published online August 8, 2017
DOI https://doi.org/ 10.1055/s-0037-1605551. ISSN 2282-4324.
Copyright @ 2017 Georg Thieme Verlag KG Stuttgart · New York

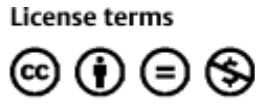


Another concept that historically led to a large use of this procedure concerns the role that the intercondylar volume would play in the incidence of ACL injuries. Nevertheless, no univocal data is supporting this hypothesis, and the addition of notchplasty to reduce the reinjury risk is not supported. ${ }^{10-14}$ Conversely, most literature agrees upon the utility of notchplasty in the management of arthrofibrosis and cases of chronic instability or revision ACLR, whereas the intercondylar notch may be characterized by the presence of osteophytes. ${ }^{3,15-18}$

We designed this article with the aim to summarize the current literature evidence concerning the effects of notchplasty on the clinical outcome of primary ACLR.

\section{Methods}

We reviewed the literature published from January 1990 to July 2015 using the Cochrane Database of Systematic Reviews, the Cochrane Central Register of Controlled Trials, PubMed, and MEDLINE. Our purpose was to identify and include all English language studies concerning the effects of the notchplasty on ACLR. Two independent reviewers conducted the search separately, using the following search strategy: "ACL" OR "anterior cruciate ligament" OR "ACL reconstruction" OR "anterior cruciate ligament reconstruction" AND "notch" OR "notchplasty" OR "intercondylar notch."

We included randomized and nonrandomized trials, case series, technical notes, biomechanical studies, and articles in which the primary outcome measure was an imaging modality (plain radiography, computed tomography scan, magnetic resonance imaging scan, three-dimensional analysis, and/or computer navigation). We excluded abstracts, letters, reviews, non-English language publications, articles published before 1990, and expert opinions (level V evidence).

Each included article was reviewed in its entirety, and all emerged risks, benefits, advantages, and/or disadvantages of notchplasty were extracted and tabulated.

Our search identified 531 abstracts or full-text articles. These articles were reviewed and cross-referenced to exclude repeated references. On the basis of titles, 457 studies were excluded. Abstract of the remaining 74 considered pertinent articles were analyzed, leading to a further exclusion of 33 articles. Full text of 41 relevant abstracts was obtained and reviewed to determine eligibility. The last screening based on the full-text review conducted to exclude 27 more articles. Reference sections of all accessed articles were then searched for any undetected study and the remaining 16 articles ${ }^{5,11,16-29}$ met the inclusion criteria and were analyzed in this review (-Fig. 1).

\section{Results}

Our search identified 531 abstracts or full-text articles. These articles were reviewed and cross-referenced to exclude repeated references. On the basis of the titles, 457 studies were excluded. Abstract of the remaining 74 considered pertinent articles were analyzed, leading to further 33

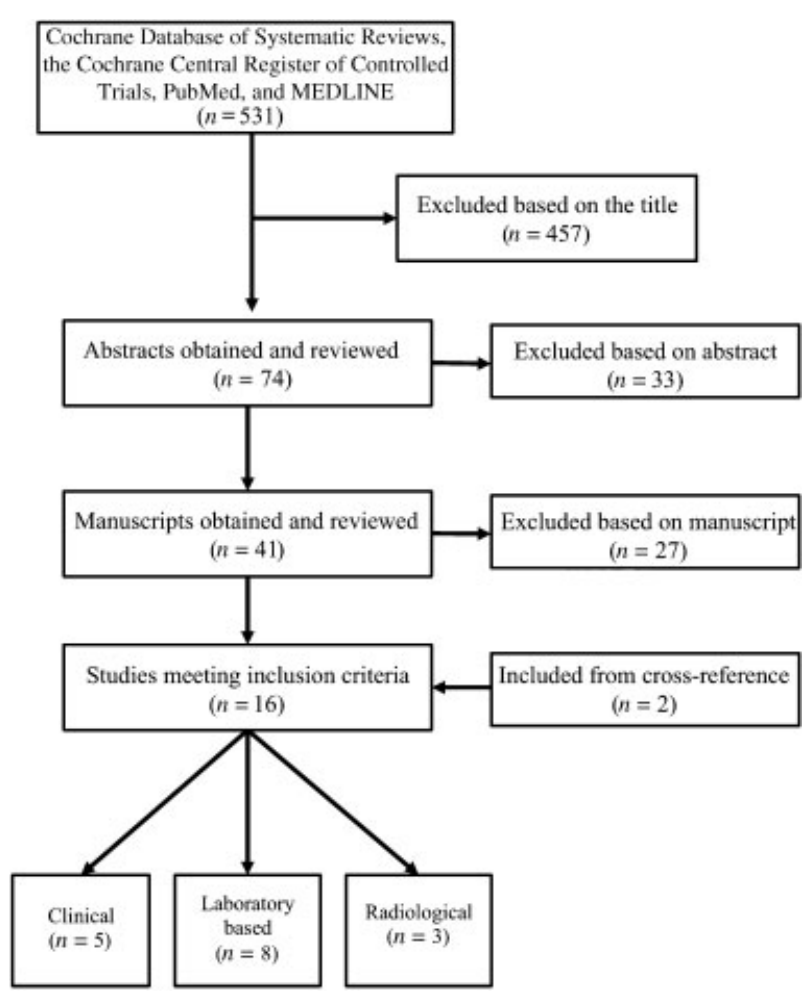

Fig. 1 Flow diagram detailing the results of the literature search.

exclusions. Full text of 41 relevant abstracts was obtained and reviewed to determine eligibility. The last screening based on the full-text review conducted to exclude 27 more manuscripts. Reference sections of all accessed articles were then searched for any undetected study and 16 articles ${ }^{5,11,16-29}$ met the inclusion criteria and were analyzed in this review ( $\mathbf{- F i g . 1}$ ). The articles were divided into laboratory-based studies, radiological studies, and clinical studies. Characteristics of included studies were recorded and summarized in - Table $\mathbf{1}$.

\section{Laboratory-Based Studies}

Fitch et $\mathrm{al}^{23}$ first evaluated the effect of notchplasty in stable and unstable canine stifles. However, LaPrade et $\mathrm{al}^{27}$ first raised concern about the effects of aggressive intercondylar notchplasty in an animal study. They reported subsynovial fibrosis and loss of surface proteoglycans in those canine knees who had notchplasty, showing a detrimental role over the cartilage after this procedure; moreover, bone growth (i.e., osteophytes) was observed in the notchplasty area although the notches did not impinge and the knees had no instability, suggesting to limit the notchplasty in case of graft impingement. Asahina et al ${ }^{20}$ observed a fibrous scar tissue that covered notchplasty area, but histological examination did not show cartilage regrowth in a rabbit model.

The role of notchplasty on knee kinematic and its effects on the graft were also investigated. Keklicki et $\mathrm{al}^{26}$ evaluated loading changes of 12 porcine knee pre- and post-notchplasty after single-bundle ACLR. Using a robotic testing system, the authors compared four knee states: intact ACL, ACL-deficient, anatomic single-bundle ACLR, and anatomic 
Table 1 Characteristics of included studies

\begin{tabular}{|c|c|c|c|c|c|}
\hline Author & Year & Study design & $\begin{array}{l}\text { Level of } \\
\text { evidence }\end{array}$ & Methods & Findings \\
\hline Fitch et al ${ }^{23}$ & 1995 & $\begin{array}{l}\text { Animal } \\
\text { (interventional } \\
\text { study) }\end{array}$ & IV & $\begin{array}{l}\text { A total of } 12 \text { knees of } 6 \text { dogs } \\
\text { underwent bilateral notchplasty } \\
\text { and unilateral ACL resection. } \\
\text { Operated knees underwent loads } \\
\text { until euthanasia at } 6 \text { mo. } \\
\text { Orthopedic examination, X-ray, } \\
\text { and histopathological examination } \\
\text { were performed }\end{array}$ & $\begin{array}{l}\text { Bone refilling of the notchplasty } \\
\text { area in all the knees. In stable } \\
\text { knees, notchplasty was refilled by } \\
\text { lamellar bone covered with fibrous } \\
\text { tissue. In stable knees, notchplasty } \\
\text { was refilled by osteophytes and } \\
\text { fibrous tissue }\end{array}$ \\
\hline $\begin{array}{l}\text { LaPrade } \\
\text { et al } 27\end{array}$ & 1998 & $\begin{array}{l}\text { Animal } \\
\text { (comparative } \\
\text { study) }\end{array}$ & IV & $\begin{array}{l}\text { Three groups of } 6 \text { dogs each were } \\
\text { observed for } 6 \text { mo. Group I had a } \\
\text { sham operation. Group II had a } \\
\text { 4-mm notchplasty. Group III had a } \\
\text { 7- to 8-mm notchplasty }\end{array}$ & $\begin{array}{l}\text { Osteophytes formation in the } \\
\text { notchplasty area. Subsynovial } \\
\text { lymphocytes and plasma cells and } \\
\text { decrease in safranin O staining with } \\
\text { aggressive notchplasty }\end{array}$ \\
\hline $\begin{array}{l}\text { Asahina } \\
\text { et } \mathrm{al}^{20}\end{array}$ & 2000 & $\begin{array}{l}\text { Animal } \\
\text { (comparative } \\
\text { study) }\end{array}$ & IV & $\begin{array}{l}\text { Situ freeze-thaw model was used to } \\
\text { evaluate histological and } \\
\text { biomechanical behavior of } A C L \\
\text { after ACLR }\end{array}$ & $\begin{array}{l}\text { Notchplasty area was covered with } \\
\text { soft tissue }\end{array}$ \\
\hline $\begin{array}{l}\text { Keklikci } \\
\text { et } \mathrm{al}^{26}\end{array}$ & 2013 & $\begin{array}{l}\text { Laboratory } \\
\text { (biomechani- } \\
\text { cal study) }\end{array}$ & IV & $\begin{array}{l}\text { Knees with different } A C L \\
\text { configuration (intact or deficient or } \\
\text { reconstructed with or without } \\
\text { notchplasty) were evaluated and } \\
\text { compared }\end{array}$ & $\begin{array}{l}\text { Notchplasty may cause anterior } \\
\text { laxity }\end{array}$ \\
\hline Markolf et al ${ }^{8}$ & 2002 & $\begin{array}{l}\text { Laboratory } \\
\text { (biomechani- } \\
\text { cal cadaveric } \\
\text { study) }\end{array}$ & IV & $\begin{array}{l}\text { Performed loading test after } 2 \mathrm{~mm} \\
\text { and } 4 \mathrm{~mm} \text { notchplasty following } \\
\text { ACLR, to evaluate graft forces and } \\
\text { knee laxity }\end{array}$ & $\begin{array}{l}\text { After notchplasty, a higher level of } \\
\text { graft pretension is necessary to } \\
\text { restore normal laxity at } 30^{\circ} \text { of } \\
\text { flexion. This increased level of } \\
\text { pretension, combined with } \\
\text { changes in graft excursion, } \\
\text { produced dramatic increases in } \\
\text { graft force when the knee was } \\
\text { flexed to } 90 \text { degrees }\end{array}$ \\
\hline Hame et $\mathrm{al}^{7}$ & 2003 & $\begin{array}{l}\text { Laboratory } \\
\text { (biomechani- } \\
\text { cal cadaveric } \\
\text { study) }\end{array}$ & IV & $\begin{array}{l}\text { Analyzed BPTB graft excursion in } \\
\text { three different femoral tunnels } \\
\text { positions, at different degree of knee } \\
\text { flexion, before and after } 2 \mathrm{~mm} \\
\text { notchplasty and they compared the } \\
\text { results with native ACL excursion }\end{array}$ & $\begin{array}{l}\text { After notchplasty, with knee } \\
\text { flexion ranging from } 20 \text { to } \\
90 \text { degrees a greater mean graft } \\
\text { excursion in all three tunnels } \\
\text { positions was observed }\end{array}$ \\
\hline Seo et $\mathrm{al}^{9}$ & 2014 & $\begin{array}{l}\text { Animal } \\
\text { (comparative } \\
\text { study) }\end{array}$ & IV & $\begin{array}{l}20 \text { specimens equally divided into } \\
\text { two groups. One group received } \\
\text { notchplasty. Specimens were } \\
\text { undergone to cyclic loading test, } \\
\text { and femoral tunnels changes were } \\
\text { evaluated with CT scan }\end{array}$ & $\begin{array}{l}\text { Notchplasty lead to a widening of } \\
\text { the femoral tunnel following cyclic } \\
\text { loading test that stimulates an } \\
\text { aggressive rehabilitation }\end{array}$ \\
\hline Dugas et $\mathrm{al}^{5}$ & 2014 & $\begin{array}{l}\text { Laboratory } \\
\text { (controlled } \\
\text { study) }\end{array}$ & IV & $\begin{array}{l}\text { CT scans compared femoral tunnel } \\
\text { placement with the native } A C L \\
\text { footprint before and after } \\
\text { notchplasty }\end{array}$ & $\begin{array}{l}\text { No differences found in coverage } \\
\text { area of the native } A C L \text { between } \\
\text { transtibial and anteromedial } \\
\text { femoral tunnel placement after } \\
\text { notchplasty }\end{array}$ \\
\hline $\begin{array}{l}\text { Dahlstedt } \\
\text { et } \mathrm{al}^{22}\end{array}$ & 1990 & $\begin{array}{l}\text { Radiological } \\
\text { (case series) }\end{array}$ & IV & $\begin{array}{l}\text { CT evaluation was performed in } \\
\text { patients undergoing ACLR with a } \\
\text { bovine tendon prosthesis } \\
\text { (Xenograft } ® \text { ) or a } \\
\text { polytetrafluoroethylene (Goretex } ®) \\
\text { ligament prosthesis and notchplasty, } \\
\text { at a mean follow-up of } 4 \mathrm{y}\end{array}$ & $\begin{array}{l}\text { Bony regrowth is possible in } \\
\text { unstable knees. However, in stable } \\
\text { knees the notch stays open }\end{array}$ \\
\hline Mann et $\mathrm{al}^{28}$ & 1999 & $\begin{array}{l}\text { Radiological } \\
\text { (case series) }\end{array}$ & IV & $\begin{array}{l}\text { CT evaluation was performed } \\
\text { preoperatively, postoperatively } \\
\text { and at last follow-up (at least } 1 \\
\text { year) in patients who undergoing }\end{array}$ & $\begin{array}{l}\text { No significant regrowth of the } \\
\text { intercondylar notch dimensions } \\
\text { between } 1 \mathrm{wk} \text { and } 1 \mathrm{y} \\
\text { postoperatively }\end{array}$ \\
\hline
\end{tabular}


Table 1 (Continued)

\begin{tabular}{|c|c|c|c|c|c|}
\hline Author & Year & Study design & $\begin{array}{l}\text { Level of } \\
\text { evidence }\end{array}$ & Methods & Findings \\
\hline & & & & $\begin{array}{l}\text { ACLR with BPTB and at least } 5 \mathrm{~mm} \\
\text { notchplasty }\end{array}$ & \\
\hline May et $\mathrm{al}^{30}$ & 1997 & $\begin{array}{l}\text { Clinical (case } \\
\text { series) }\end{array}$ & IV & $\begin{array}{l}\text { Patients were evaluated with MRI } \\
6 \text { months after ACLR with at least } \\
3 \text { mm notchplasty }\end{array}$ & $\begin{array}{l}\text { Within } 6 \text { mo of surgery a layer of } \\
\text { cortical bone regrowth in the } \\
\text { notchplasty area }\end{array}$ \\
\hline Ahn et al $^{19}$ & 2007 & $\begin{array}{l}\text { Clinical } \\
\text { (second-look } \\
\text { arthroscopy) }\end{array}$ & IV & $\begin{array}{l}\text { Second-look arthroscopy was } \\
\text { performed in } 208 \text { patients who had } \\
\text { ACLR }\end{array}$ & $\begin{array}{l}\text { Notch reformation in } 40 \% \text { of the } \\
\text { cases }\end{array}$ \\
\hline $\begin{array}{l}\text { Muneta } \\
\text { et } \mathrm{al}^{29}\end{array}$ & 1995 & $\begin{array}{l}\text { Clinical } \\
\text { (retrospective } \\
\text { study) }\end{array}$ & IV & $\begin{array}{l}32 \text { knees (nonroofplasty group) } \\
\text { and } 11 \text { knees (roofplasty group) } \\
\text { underwent ACLR with a modified } \\
\text { over the top technique. Lysholm's } \\
\text { score, manual knee tests, ROM } \\
\text { evaluation were performed }\end{array}$ & $\begin{array}{l}\text { No differences in all evaluations } \\
\text { between the nonroofplasty and } \\
\text { roofplasty groups }\end{array}$ \\
\hline $\begin{array}{l}\text { Camillieri } \\
\text { et } \mathrm{al}^{21}\end{array}$ & 2001 & $\begin{array}{l}\text { Clinical } \\
\text { (prospective } \\
\text { case series) }\end{array}$ & II & $\begin{array}{l}\text { After ACLR } 12 \text { patients notchplasty } \\
\text { using a motorized shaver and } 12 \\
\text { patients using radiofrequency }\end{array}$ & $\begin{array}{l}\text { Notchplasty performed with } \\
\text { radiofrequency device reduce } \\
\text { blood loss after ACLR }\end{array}$ \\
\hline Pape et $a^{31}$ & 2000 & $\begin{array}{l}\text { Clinical } \\
\text { (prospective } \\
\text { study) }\end{array}$ & II & $\begin{array}{l}21 \text { patients received notchplasty, } \\
\text { and } 37 \text { did not }\end{array}$ & $\begin{array}{l}\text { Notchplasty increases of } 30 \% \text { blood } \\
\text { loss without clinical differences }\end{array}$ \\
\hline Koga et al ${ }^{4}$ & 2014 & $\begin{array}{l}\text { Clinical (cohort } \\
\text { study) }\end{array}$ & III & $\begin{array}{l}64 \text { patients with notchplasty and } \\
73 \text { without in DB-ACLR technique } \\
\text { were evaluated }\end{array}$ & $\begin{array}{l}\text { Notchplasty following DB-ACLR } \\
\text { did not has detrimental effects on } \\
\text { patellofemoral joint, but causes } \\
\text { overconstrained knee. DB-ACLR } \\
\text { without notchplasty did not create } \\
\text { loss of extension }\end{array}$ \\
\hline
\end{tabular}

Abbreviations: ACL, anterior cruciate ligament; ACLR, anterior cruciate ligament reconstruction; CT, computed tomography; DB, double-bundle; ROM, range of motion.

single-bundle ACLR with a 5-mm notchplasty. Their results showed how notchplasty can adversely affect the knee after ACLR and may lead to instability of the knee joint. In fact, they observed a greater anterior laxity after notchplasty, at different degrees of knee flexion, with no difference in external tibial rotation.

Markolf et $\mathrm{al}^{8}$ performed bench loading tests on 26 freshfrozen knee specimens to measure excursion of a bonepatellar tendon-bone (BPTB) graft, anterior-posterior laxity of the knee, and graft forces before and after performing a 2$\mathrm{mm}$ and a 4-mm notchplasty. The authors suggested removing bone as less as possible while performing notchplasty to avoid excessive pretension of the graft, which can result in high graft forces and to restore normal anterior-posterior laxity. Similarly, Hame et $\mathrm{al}^{7}$ investigated the effects of notchplasty on graft excursion patterns in 15 fresh-frozen knees. They analyzed BPTB graft excursion in three different femoral tunnels positions (10-, 11-, and 12-o'clock or 2-, 1-, and 12-o'clock), at various degree of knee flexion, before and after 2-mm notchplasty and they compared the results with native ACL excursion. No difference was observed in graft excursion between native ACL and the graft in three different femoral tunnels positions before notchplasty. After notchplasty, with knee flexion ranging from 20 to 90 degrees, a greater mean graft excursion in all three tunnels positions was observed. All grafts, after notchplasty, were tightened in flexion disregarding to tunnel positions. The authors suggested that graft forces would increase with knee flexion, suggesting removing a small portion of bone from the posterior aspect of the notch during ACLR.

Seo et $\mathrm{al}^{9}$ investigated the effect of notchplasty on tunnel widening in ACLR. They performed a laboratory study using 20 porcine specimens. Group A did not receive notchplasty, while a 2-mm notchplasty was conducted in group B. Samples were mounted on a testing machine, preloaded and subjected to 20 loading cycles followed by 1,000 loading cycles in the elastic region. High-resolution computed tomography (CT) was conducted with all samples before and after testing, and a three-dimensional model was constructed to evaluate the degree of change in the tunnel. The authors found that in the notchplasty group the mean longest diameter and dimension of the femoral tunnel significantly increased and the volumetric loss of bony structure was significantly greater than that in group A, concluding that intra-articular orifice of the femoral tunnel was enlarged after the uniaxial cyclic loading test after notchplasty. An enlarged tunnel may lead to a discrepancy between the tunnel and the graft at the tunnel opening, and this may affect graft positioning, leading to subtle changes in graft biomechanics and subsequent laxity. 
Recently, the effects of notchplasty on femoral tunnel placement with both transtibial or anteromedial techniques have been investigated in cadaveric knees using $\mathrm{CT}{ }^{5}$ No differences were found in the coverage area of the native ACL between transtibial and anteromedial femoral tunnel placement after notchplasty, showing that transtibial drilling of femoral tunnel is a reliable technique to place the tunnel in anatomic position.

\section{Radiological Studies}

In 1990, Dahlstedt et $\mathrm{al}^{22}$ showed that CT scan is a reliable tool to study the notch width. The authors performed a CT examination on 21 patients undergoing ACLR with notchplasty, at a mean follow-up of 4 years. The authors showed that despite some bony regrowth is possible in unstable knees, the notch stays open in stable knees, thus emphasizing the importance of performing notchplasty during ACLR. Mann et $\mathrm{al}^{28}$ reported clinical and radiological (CT) outcomes after ACLR in 10 patients undergoing ACLR with BPTB. In all cases, they performed notchplasty using a curve osteotome and removed at least $5 \mathrm{~mm}$ from the lateral femoral condyle. All patients underwent CT evaluation preoperatively, postoperatively and at last follow-up (at least 1 year). At last follow-up, the notch was found not decreased in dimension. Conversely, the regrowth of the notchplasty area was demonstrated by May et al. ${ }^{30}$ The authors evaluated 33 patients with magnetic resonance imaging (MRI) six months after ACLR. All reconstructions were performed using BPTB autografts, and all notchplasties involved removal of at least $3 \mathrm{~mm}$ of bone from the roof and lateral wall of the intercondylar notch using an osteotome and a high-speed burr. MRI scans were obtained 1 week after surgery in 25 patients and at 6 months in all patients. In six patients a second-look arthroscopy was performed to search for clinical signs of graft impingement. At 6 months, a regrowth of tissue, which was not present in the postsurgery MRI scans, was observed in the notchplasty area.

\section{Clinical Studies}

Ahn et al $^{19}$ observed a notch regrowth after a second-look arthroscopy in 40\% (86/209) of the knees examined, after a mean of 21.2 months (range, 14-70 months) from ACLR and notchplasty. In 15 cases the reformed notch was more than $3 \mathrm{~mm}$, and in 55 cases the graft impinged with the notch. The graft showed a partial tear in 21 patients (10\%). No correlation was observed between the type of graft (hamstrings or BPTB) and the reformation rate of the notch.

Muneta et $\mathrm{al}^{29}$ evaluated the effects of roofplasty after ACLR with the over the top technique; they found no difference between reconstruction with or without roofplasty in terms of clinical and functional evaluation.

Two studies evaluated the effects of notchplasty on postoperative blood loss after ACLR. ${ }^{21,31}$ Camillieri et al $^{21}$ evaluated 24 patients undergoing ACLR with BPTB. Patients were randomized into two groups: 12 patients underwent notchplasty using a motorized shaver, and 12 patients underwent notchplasty using a radiofrequency instrument. Postoperative bleeding was significantly higher in patients who received notchplasty using a motorized shaver. No difference in the range of motion was observed 1 month postoperatively. The authors did not report clinical and functional results over this period. Furthermore, Pape et $\mathrm{al}^{31}$ compared blood loss after ACLR with and without notchplasty. They divided 58 consecutive patients undergoing ACLR with BPTB into two groups: 21 received notchplasty, and 37 did not. The notchplasty group showed significant postoperative blood loss, in terms of drainage volume and differential serum hemoglobin and hematocrit levels compared with the other group. However, no differences were found at 12 months postoperatively in International Knee Documentation Committee (IKDC) score, Lysholm's score, and KT-1000 assessment.

Recently, only one study from Koga et $\mathrm{al}^{4}$ investigated the effects of notchplasty in double-bundle ACLR. Authors conducted a cohort study, hypothesizing that 2-mm notchplasty following double-bundle ACLR would reduce the risk of loss of extension and improve graft healing and knee stability compared with ACLR without notchplasty. The authors divided 137 patients into two groups: the first one (64 patients) with notchplasty and the second one (control group, 73 patients) without notchplasty. Interestingly, the notchplasty group showed a significant extension loss compared with control group, and six patients needed to undergo an additional surgery to solve this problem. Moreover, the notchplasty group showed better stability measured with KT-1000, but six patients among this group had an overconstrained knee compared with one in the control group, probably due to bleeding from the notchplasty area leading to fibrosis of the infrapatellar fat pad. Although notchplasty is performed to avoid impingement and loss of extension, the results of this study showed a restricting role of notchplasty in double-bundle ACLR.

\section{Discussion}

Notchplasty is an ancillary surgical procedure that consists of reshaping and widening of the intercondylar femoral notch, historically developed and performed with the aim to avoid ACL graft impingement and improve visualization of the lateral wall of the femoral notch during ACLR surgery. ${ }^{25,27}$ Although notchplasty is still widely performed, mainly when a transtibial technique is used, ${ }^{2}$ little is known about its effect on the outcomes of ACLR and if it is really useful, needless, or even harmful. Long-term consequences of this procedure are still unknown; ${ }^{21,31}$ moreover, there is no evidence that it can be useful in avoiding impingement. ${ }^{20,26,31}$ Conversely, several studies reported regrowth of the notch, ${ }^{19,27,30}$ detrimental effects on the near cartilage when notchplasty is too aggressive, ${ }^{20,27}$ negative biomechanical effects on the graft, and unexpected extension deficit after ACLR, that is the opposite effect that notchplasty advocates would obtain. This could be explained by the postoperative bleeding induced by notchplasty that may lead to arthrofibrosis or by the shifting of the femoral insertion site, from the true, correct site to one less anatomical with consequent biomechanical deleterious effects. ${ }^{4,7,8,21,26,31}$ Furthermore, widening of the femoral 
tunnel after notchplasty has been reported and it may affect graft positioning, leading to subtle changes in graft biomechanics and knee laxity. ${ }^{9}$ To better preserve and restore the anatomy, it would be beneficial to place the tunnels and the graft in the correct position and to choose the right size of the graft rather than performing notchplasty.

Some useful suggestions have been provided to avoid notchplasty while performing ACLR, such as: respecting the graft free zone in the tibial footprint; ${ }^{32}$ placing the tibial bone tunnel for the anteromedial bundle as medially as possible within its footprint to avoid wall impingement in double-bundle technique; ${ }^{33}$ avoiding double-bundle technique in cases of narrow notch $(<12 \mathrm{~mm}) ;^{34}$ if a good view of the footprint is difficult to achieve, consider using an additional portal (three-portals technique) ${ }^{35}$ in transtibial technique, if impingement is unavoidable or if it is present after graft fixation, remove bone as less as possible from the intercondylar notch; $;, 8,36$ avoid performing notchplasty in anatomical techniques; ${ }^{4,32,35}$ choose the right size of the graft to avoid notch/graft mismatch and to decrease the incidence of cyclops lesions. ${ }^{24}$

Notchplasty is certainly beneficial in the management of arthrofibrosis, in cases of postoperative roof impingement with the aim to preserve the graft and in cases of clear bony spurs of the notch both in primary (usually chronic rupture) and revision surgery (osteoarthritis). ${ }^{15-18,37}$

This study has several limitations. First, the level of evidence of available literature is poor, with very few clinical studies. The second is the heterogeneity of such articles. Finally, the paucity of quantitative data made almost impossible to compare and objectively measure outcomes, thus limiting valid conclusions.

Despite the limitations mentioned earlier, we can affirm that notchplasty may alter knee biomechanics, overconstrain the knee, and overload the graft with the consequent higher risk of graft failure or postoperative knee stiffness. Moreover, postoperative bleeding due to notchplasty may determine loss of extension or arthrofibrosis. In conclusion, we suggest carefully considering risks related to notchplasty during primary ACLR, reserving it for the surgical management of arthrofibrosis, the presence of notch osteophytosis, and revision surgery.

\section{References}

1 Siegel L, Vandenakker-Albanese C, Siegel D. Anterior cruciate ligament injuries: anatomy, physiology, biomechanics, and management. Clin J Sport Med 2012;22(04):349-355

2 Zuiderbaan HA, Khamaisy S, Nawabi DH, et al. Notchplasty in anterior cruciate ligament reconstruction in the setting of passive anterior tibial subluxation. Knee 2014;21(06):1160-1165

3 Fu FH, Bennett CH, Ma CB, Menetrey J, Lattermann C. Current trends in anterior cruciate ligament reconstruction. Part II. Operative procedures and clinical correlations. Am J Sports Med 2000;28(01):124-130

4 Koga $\mathrm{H}$, Muneta T, Yagishita K, et al. Effect of notchplasty in anatomic double-bundle anterior cruciate ligament reconstruction. Am J Sports Med 2014;42(08):1813-1821

5 Dugas JR, Pace JL, Bolt B, Wear SA, Beason DP, Cain EL Jr. Evaluation and comparison of femoral tunnel placement during anterior cruciate ligament reconstruction using 3-dimensional computed tomography: effect of notchplasty on transtibial and medial portal drilling. Orthop J Sports Med 2014;2(03). Doi: $10.1177 / 2325967114525572$

6 Berns GS, Howell SM. Roofplasty requirements in vitro for different tibial hole placements in anterior cruciate ligament reconstruction. Am J Sports Med 1993;21(02):292-298

7 Hame SL, Markolf KL, Hunter DM, Oakes DA, Zoric B. Effects of notchplasty and femoral tunnel position on excursion patterns of an anterior cruciate ligament graft. Arthroscopy 2003;19(04): 340-345

8 Markolf KL, Hame SL, Hunter DM, Oakes D, Gause P. Biomechanical effects of femoral notchplasty in anterior cruciate ligament reconstruction. Am J Sports Med 2002;30(01):83-89

9 Seo YJ, Yoo YS, Kim YS, et al. The effect of notchplasty on tunnel widening in anterior cruciate ligament reconstruction. Arthroscopy 2014;30(06):739-746

10 Al-Saeed O, Brown M, Athyal R, Sheikh M. Association of femoral intercondylar notch morphology, width index and the risk of anterior cruciate ligament injury. Knee Surg Sports Traumatol Arthrosc 2013;21(03):678-682

11 Lombardo S, Sethi PM, Starkey C. Intercondylar notch stenosis is not a risk factor for anterior cruciate ligament tears in professional male basketball players: an 11-year prospective study. Am J Sports Med 2005;33(01):29-34

12 Tanzer M, Lenczner E. The relationship of intercondylar notch size and content to notchplasty requirement in anterior cruciate ligament surgery. Arthroscopy 1990;6(02):89-93

13 Wolf MR, Murawski CD, van Diek FM, van Eck CF, Huang Y, Fu FH. Intercondylar notch dimensions and graft failure after single- and double-bundle anterior cruciate ligament reconstruction. Knee Surg Sports Traumatol Arthrosc 2015;23(03): 680-686

14 Zeng C, Gao SG, Wei J, et al. The influence of the intercondylar notch dimensions on injury of the anterior cruciate ligament: a meta-analysis. Knee Surg Sports Traumatol Arthrosc 2013; 21(04):804-815

15 León HO, Blanco CE, Guthrie TB, Martínez OJ. Intercondylar notch stenosis in degenerative arthritis of the knee. Arthroscopy 2005; 21(03):294-302

16 Mauro CS, Irrgang JJ, Williams BA, Harner CD. Loss of extension following anterior cruciate ligament reconstruction: analysis of incidence and etiology using IKDC criteria. Arthroscopy 2008; 24(02):146-153

17 Mayr HO, Rueschenschmidt M, Seil R, et al. Indications for and results of arthroscopy in the arthritic knee: a European survey. Int Orthop 2013;37(07):1263-1271

18 Quasnichka HL, Anderson-MacKenzie JM, Tarlton JF, Sims TJ, Billingham ME, Bailey AJ. Cruciate ligament laxity and femoral intercondylar notch narrowing in early-stage knee osteoarthritis. Arthritis Rheum 2005;52(10):3100-3109

19 Ahn JH, Yoo JC, Yang HS, Kim JH, Wang JH. Second-look arthroscopic findings of 208 patients after ACL reconstruction. Knee Surg Sports Traumatol Arthrosc 2007;15(03):242-248

20 Asahina S, Muneta T, Ezura Y. Notchplasty in anterior cruciate ligament reconstruction: an experimental animal study. Arthroscopy 2000;16(02):165-172

21 Camillieri G, Margheritini F, Maresca G, Mariani PP. Postoperative bleeding following notchplasty in anterior cruciate ligament reconstruction: thermal radio frequency versus powered instrumentation. Knee Surg Sports Traumatol Arthrosc 2001;9(01): $12-14$

22 Dahlstedt L, Dalén N, Dahlborn M, Nilsson T. Value of intercondylar notch plasty. CT studies and peroperative measurements of 127 knees. Acta Orthop Scand 1990;61(06):558-561

23 Fitch RB, Montgomery RD, Kincaid SA, et al. The effect of intercondylar notchplasty on the normal canine stifle. Vet Surg 1995; 24(02):156-164 
24 Fujii M, Furumatsu T, Miyazawa S, et al. Intercondylar notch size influences cyclops formation after anterior cruciate ligament reconstruction. Knee Surg Sports Traumatol Arthrosc 2015;23 (04):1092-1099

25 Howell SM. Principles for placing the tibial tunnel and avoiding roof impingement during reconstruction of a torn anterior cruciate ligament. Knee Surg Sports Traumatol Arthrosc 1998;6(Suppl 1): S49-S55

26 Keklikci K, Yapici C, Kim D, Linde-Rosen M, Smolinski P, Fu FH. The effect of notchplasty in anterior cruciate ligament reconstruction: a biomechanical study in the porcine knee. Knee Surg Sports Traumatol Arthrosc 2013;21(08):1915-1921

27 LaPrade RF, Terry GC, Montgomery RD, Curd D, Simmons DJ. Winner of the Albert Trillat Young Investigator Award. The effects of aggressive notchplasty on the normal knee in dogs. Am J Sports Med 1998;26(02):193-200

28 Mann TA, Black KP, Zanotti DJ, Barr M, Teater T. The natural history of the intercondylar notch after notchplasty. Am J Sports Med 1999;27(02):181-188

29 Muneta T, Yamamoto H, Ishibashi T, Asahina S, Murakami S, Furuya K. The effects of tibial tunnel placement and roofplasty on reconstructed anterior cruciate ligament knees. Arthroscopy 1995;11(01):57-62

30 May DA, Snearly WN, Bents R, Jones R. MR imaging findings in anterior cruciate ligament reconstruction: evaluation of notchplasty. Am J Roentgenol 1997;169(01):217-222
31 Pape D, Seil R, Adam F, et al. Blood loss in anterior cruciate ligament $(\mathrm{ACL})$ reconstruction with and without intercondylar notchplasty: does it affect the clinical outcome? Arch Orthop Trauma Surg 2001;121(10):574-577

32 Van der Bracht H, Bellemans J, Victor J, Verhelst L, Page B, Verdonk P. Can a tibial tunnel in ACL surgery be placed anatomically without impinging on the femoral notch? A risk factor analysis. Knee Surg Sports Traumatol Arthrosc 2014;22(02): 291-297

33 Udagawa K, Niki Y, Enomoto H, Toyama Y, Suda Y. Factors influencing graft impingement on the wall of the intercondylar notch after anatomic double-bundle anterior cruciate ligament reconstruction. Am J Sports Med 2014;42(09):2219-2225

34 Van Eck CF, Martins CA, Kopf S, Lertwanich P, Fu FH, Tashman S. Correlation between the 2-dimensional notch width and the 3dimensional notch volume: a cadaveric study. Arthroscopy 2011; 27(02):207-212

35 Cohen SB, Fu FH. Three-portal technique for anterior cruciate ligament reconstruction: use of a central medial portal. Arthroscopy 2007;23(03):325.e1-325.e5

36 Howell SM. Arthroscopic roofplasty: a method for correcting an extension deficit caused by roof impingement of an anterior cruciate ligament graft. Arthroscopy 1992;8(03):375-379

37 Shelbourne KD, Patel DV, Martini DJ. Classification and management of arthrofibrosis of the knee after anterior cruciate ligament reconstruction. Am J Sports Med 1996;24(06):857-862 